\title{
Fumaric acid production by fermentation
}

\author{
Carol A. Roa Engel • Adrie J. J. Straathof • \\ Tiemen W. Zijlmans • Walter M. van Gulik • \\ Luuk A. M. van der Wielen
}

Received: 17 October 2007 /Revised: 19 December 2007 / Accepted: 20 December 2007 / Published online: 24 January 2008

(C) The Author(s) 2008

\begin{abstract}
The potential of fumaric acid as a raw material in the polymer industry and the increment of cost of petroleum-based fumaric acid raises interest in fermentation processes for production of this compound from renewable resources. Although the chemical process yields $112 \% \mathrm{w} / \mathrm{w}$ fumaric acid from maleic anhydride and the fermentation process yields only $85 \% \mathrm{w} / \mathrm{w}$ from glucose, the latter raw material is three times cheaper. Besides, the fermentation fixes $\mathrm{CO}_{2}$. Production of fumaric acid by Rhizopus species and the involved metabolic pathways are reviewed. Submerged fermentation systems coupled with product recovery techniques seem to have achieved economically attractive yields and productivities. Future prospects for improvement of fumaric acid production include metabolic engineering approaches to achieve low $\mathrm{pH}$ fermentations.
\end{abstract}

Keywords Fumaric acid · Fermentation - Rhizopus species . Maleate isomerase $\cdot$ Product recovery

\section{Introduction}

Fumaric acid (Fig. 1) is a naturally occurring organic acid. It was first isolated from the plant Fumaria officinalis, from which it derives its name. Many microorganisms produce

C. A. Roa Engel • A. J. J. Straathof $(\bowtie) \cdot$ T. W. Zijlmans •

W. M. van Gulik $\cdot$ L. A. M. van der Wielen

Department of Biotechnology, Delft University of Technology,

Julianalaan 67 ,

2628 BC Delft, The Netherlands

e-mail: A.J.J.Straathof@tudelft.nl fumaric acid in small amounts, as it is a key intermediate in the citrate cycle. Fumaric acid is also known as $(E)-2-$ butenedioic acid or trans-1,2-ethylenedicarboxylic acid. Sometimes the term "fumarates" is also used. In this review, this general term is not used to describe fumaric acid esters like dimethyl fumarate but only to describe the salts of fumaric acid (sodium fumarate, calcium fumarate).

Currently, fumaric acid is produced chemically from maleic anhydride, which in turn is produced from butane. However, as petroleum prices are rising rather quickly, maleic anhydride as a petroleum derivative has increased in price as well (Anonymous 2007). This situation has caused a renewed interest in the fumaric acid production by fermentation that was operational during the 1940 s (Goldberg et al. 2006), but was discontinued and replaced by petrochemical processes. The fermentation process is also interesting because it involves carbon dioxide fixation, as will be discussed later. Fungi are known for their organic acid-producing capability and have been used in fermentation processes for fumaric acid production.

Production by filamentous fungi of organic acids, including fumaric acid, has recently been reviewed (Magnuson and Lasure 2004; Goldberg et al. 2006). These reviews focused on the microorganisms with their associated metabolic pathways. In contrast, the current review focuses on development of fumaric acid production processes. After summarizing fumaric acid properties, applications, and production, metabolic pathways for fumaric acid production will be discussed only briefly before turning to fermentation performance of the most prominent fumaric acid-producing strains. Furthermore, different methods that have been studied to optimize fermentation processes will be mentioned, and future prospects for process development will be discussed. 
Fig. 1 Current applications of fumaric acid production. Miscellaneous include: lubricating oil, inks, lacquers, carboxylating agent for styrenebutadiene rubber, personal care additives. $a$ Anonymous 2007; $b$ Willke and Vorlop 2004

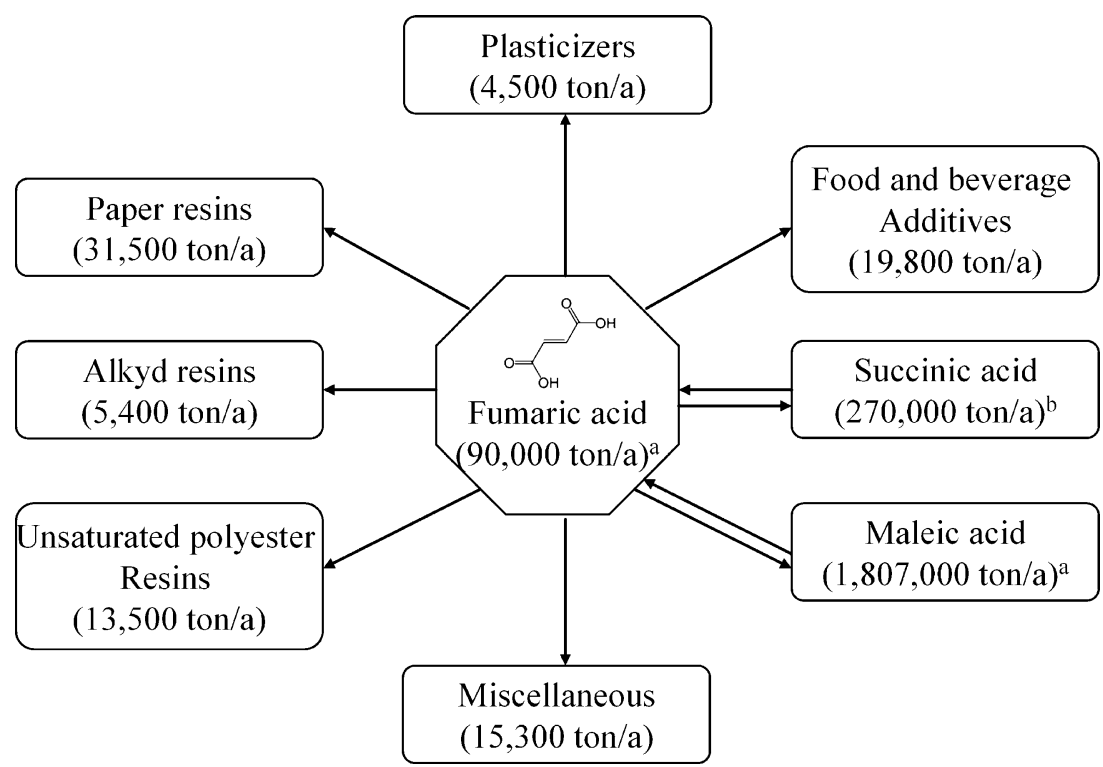

\section{Properties and applications of fumaric acid}

Because of its structure (a carbon-carbon double bond and two carboxylic acid groups), fumaric acid has many potential industrial applications (Fig. 1). It can act as starting material for polymerization and esterification reactions (www.the-innovation-group.com/ChemProfiles/ Fumaric\%20Acid.htm; 10/06/07).

As raw material for polymerization, especially in the production of unsaturated polyester resins, maleic anhydride is currently preferred to fumaric acid because maleic anhydride [1.46-1.63 \$/kg; (Anonymous 2007)] is cheaper than fumaric acid, the latter historically being around $10 \%$ more expensive than maleic anhydride (http://www. chemweek.com/inc/articles/t/2007/04/04/04/022.html). However, fumaric acid could be a better option for the polymer industry among other carboxylic acids or their derivatives because of its nontoxic nature. In addition, special properties like greater hardness in the polymer structure can be achieved when fumaric acid is used (www. the-innovation-group.com/ChemProfiles/Fumaric\%20Acid. $\mathrm{htm} ; 10 / 06 / 07)$. In addition to polymerization, there are two potentially new applications for fumaric acid and both require a different grade of purity of it. The first is as a medicine to treat psoriasis, a skin condition (Altmeyer et al. 1994; Mrowietz et al. 1998). Psoriatic individuals are unable to produce fumaric acid in their body (which is not the case in normal individuals) due to a certain biochemical defect that interferes with adequate fumaric acid production in the skin. Therefore, psoriatic individuals need to take orally fumaric acid in the form of fumaric acid monoethyl or dimethyl ester to treat their disease. The second potential application of fumaric acid is as supplement in cattle feed. Recent studies indicate that a large reduction in the methane emissions of cattle can be achieved (up to $70 \%$ ), if this cattle receives fumaric acidbased additive as a supplement in their diet (Mcginn et al. 2004). This could greatly reduce the total emission of methane, as farm animals are responsible for $14 \%$ of the methane emission caused by human activity.

Fumaric acid, together with the related succinic and malic acids, has been identified as one of the top ten building block chemicals that can be produced from sugars via biological or chemical conversion (Werpy and Petersen 2004). Compared to these other dicarboxylic acids, fumaric acid has a low aqueous solubility $\left[7 \mathrm{~g} / \mathrm{kg}\right.$ at $25^{\circ} \mathrm{C} ; 89 \mathrm{~g} / \mathrm{kg}$ at $100^{\circ} \mathrm{C}$ (Stephen 1965)] and low $\mathrm{p} K_{\mathrm{a}}$ values [3.03 and 4.44 (Lohbeck et al. 1990)], which are properties that can be exploited for product recovery.

\section{Fumaric acid production by petrochemical routes}

Fumaric acid is currently produced by isomerization of maleic acid, which is produced from maleic anhydride. Maleic anhydride, in turn, is industrially produced by catalytic oxidation of suitable hydrocarbons in the gas phase. Benzene used to be the predominant starting material, but oxidation of $n$-butane or $n$-butane- $n$-butene mixtures has become more important in recent years (Lohbeck et al. 1990). The butane oxidation reaction equation to maleic anhydride is: $\mathrm{C}_{4} \mathrm{H}_{10}+3.5 \mathrm{O}_{2} \rightarrow$ $\mathrm{C}_{4} \mathrm{H}_{2} \mathrm{O}_{3}+4 \mathrm{H}_{2} \mathrm{O}$.

In the most common maleic anhydride process, the catalyst is embedded in fixed-bed tubular reactors. The catalysts applied in this process are based on vanadium and phosphorus oxides. In this process, water is formed as a byproduct, and a fairly small amount of it can be directly 
liquefied from the reaction gas by partial condensation. Organic solvents absorb maleic anhydride contained in the reaction gas. More than $98 \%$ of the anhydride can be absorbed in this way. The solvent-anhydride mixture is then subjected to fractional distillation to separate maleic anhydride from the solvent, and the latter is returned to the absorption column (Lohbeck et al. 1990). The thus obtained pure maleic anhydride is then hydrolyzed into maleic acid according to the reaction equation $\mathrm{C}_{4} \mathrm{H}_{2} \mathrm{O}_{3}+\mathrm{H}_{2} \mathrm{O} \rightarrow$ $\mathrm{C}_{4} \mathrm{H}_{4} \mathrm{O}_{4}$.

Subsequently, the maleic acid is converted almost quantitatively by thermal or catalytic cis-trans isomerization into fumaric acid (Lohbeck et al. 1990). The most common catalysts used are mineral acids, peroxy compounds, and thiourea. The crude fumaric acid obtained in this way is purified by crystallization from water (Fig. 2). As will be shown later, a comparable purification may be used for fermentative fumaric acid production.

Production capacity of maleic anhydride in 2007 was about 1,807,000 ton/a (Anonymous 2007), with around 3\% of this being used for fumaric acid production (http:// chemicalmarketreporter.com/home/Default.asp?type = 17\&liArticleID $=2015643 \ldots ; 18 / 04 / 2007)$, corresponding to 90,000 ton/a.

\section{Enzymatic conversion of maleic acid into fumaric acid}

In the aforementioned chemical isomerization of maleic acid into fumaric acid, the conversion yield is restricted by the reaction equilibrium. This chemical conversion is occurring at high temperatures that causes formation of by-products from maleic and fumaric acids, and as a consequence, yields are below the equilibrium yields (Goto et al. 1998). This problem was the main motivation to look for a good enzyme that would facilitate isomerization, so that the equilibrium mixture would be obtained without formation of by-products.

It is known that the enzyme maleate isomerase (maleate cis-trans-isomerase) isomerizes maleic acid into fumaric acid. Microorganisms that produce maleate isomerase are Pseudomonas species (Otsuka 1961), Alcaligenes faecalis (Takamura et al. 1969), and Pseudomonas fluorescens (Scher and Lennarz 1969). However, maleate isomerase is unstable even at moderate temperatures (Takamura et al. 1969), and therefore, a heat-stable maleate isomerase is desired. Thermo-stable maleate isomerases derived from Bacillus stearothermophilus, Bacillus brevis, and Bacillus sp. MI-105 were reported by Goto et al. (1998), and according to the authors, the use of enzymes from these bacteria can improve the fumaric acid production process.

Furthermore, in a more recent study using Pseudomonas alcaligenes $\mathrm{XD}-1$, high rates of conversion of maleic acid into fumaric acid $\left(6.98 \mathrm{~g} \mathrm{~L}^{-1} \mathrm{~h}^{-1}\right)$ were reported (NakajimaKambe et al. 1997). This organism does not normally accumulate fumaric acid, but by heat treatment of the cells $\left(70^{\circ} \mathrm{C}\right.$ for $\left.1 \mathrm{~h}\right)$, they lost their fumarase activity, which otherwise would be responsible for a conversion of fumaric acid into L-malic acid. This heat treatment did not affect the maleate isomerase activity. In addition, when calcium ions were added during the conversion step, the thermal stability of maleate isomerase was increased. With
Fig. 2 Plant for fumaric acid production from malic acid. $a$ Isomerization vessel; $b$ Centrifuge; $c$ Dissolving tank; $d$ Filter; $e$ Crystallizer; $f$ Dryer (adapted from Felthouse et al. 2001)

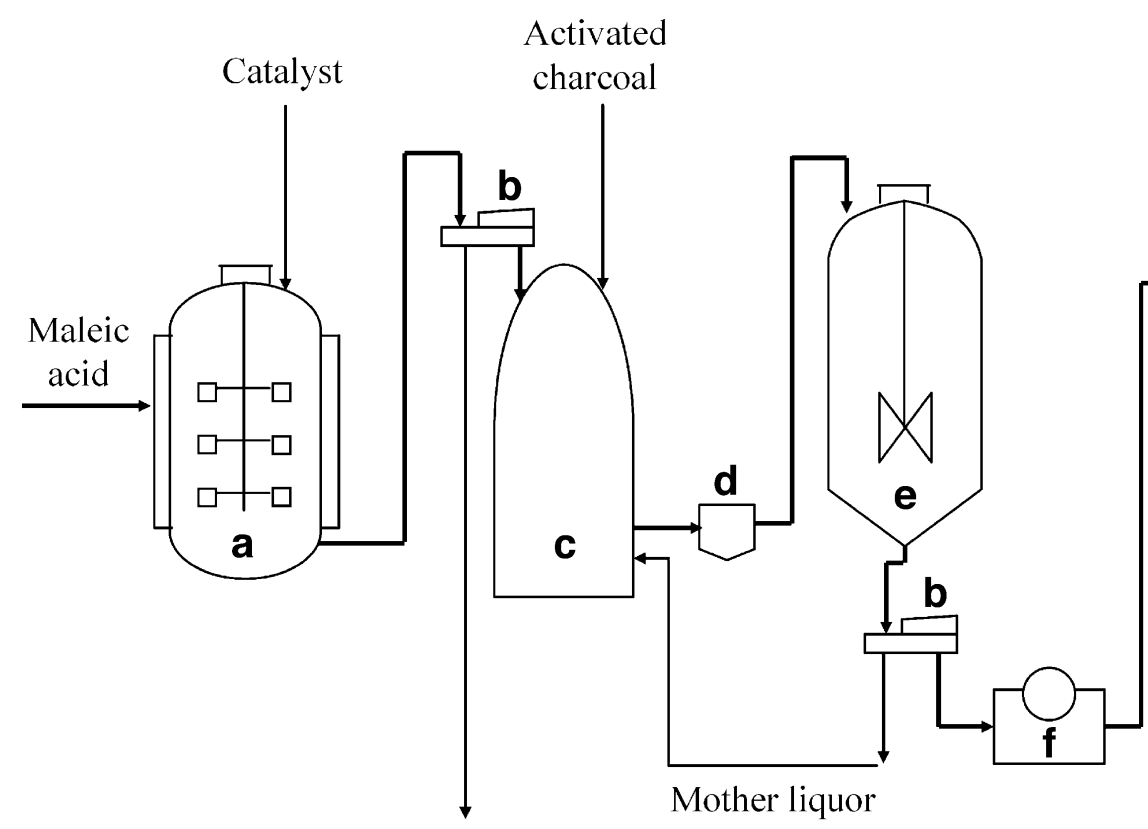

To effluent purification

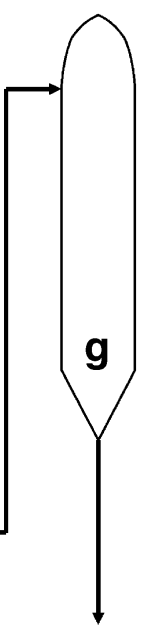

Fumaric acid 
the use of $P$. alcaligenes $\mathrm{XD}-1$, the highest reported conversion yield, $95 \%$, was achieved in the conversion of maleic acid to fumaric acid (Ichikawa et al. 2003). Immobilization of the heat-treated cells is currently under investigation.

\section{Microbial production of fumaric acid}

Fumaric acid production by fermentation was operated in the United States during the 1940s, but later, this process was discontinued and replaced by chemical synthesis from petrochemical feedstocks, the latter being explained in a previous section. Nevertheless, the continuous increase of the petroleum prices has brought back the interest in fumaric acid production by submerged fermentation (Goldberg et al. 2006). Fumaric acid production by fermentation using Rhizopus species has been patented occasionally (Waksman 1943; Kane 1943; Lubowitz and La Roe 1958; La Roe 1959; Goldberg and Stieglitz 1986). In 1989, DuPont patented an improved fermentation process producing carboxylic acids (fumaric, succinic, malic, and mixtures thereof) by controlling dissolved oxygen levels between 30 and $80 \%$ (Ling and $\mathrm{Ng}$ 1989).

In the field of fumaric acid production by fermentation, there are many aspects determining the productivity of the fermentation process, such as the applied microbial strain and its morphology, the use of a neutralizing agent, and the applied feedstock. Those aspects are reviewed and analyzed in more detail in the following sections.
Fumaric acid-producing strains

After the discovery of fumaric acid production in Rhizopus nigricans by Felix Ehrlich in 1911, Foster and Waksman (1938) screened 41 strains from eight different genera to identify high fumarate producing strains. The fumarateproducing genera identified were Rhizopus, Mucor, Cunninghamella, and Circinella species. Among these strains, Rhizopus species (nigricans, arrhizus, oryzae, and formosa) were the best-producing ones, yielding fumaric acid under aerobic and anaerobic conditions (Foster and Waksman 1938; Rhodes et al 1959; Kenealy et al. 1986; Cao et al. 1996; Carta et al. 1999). Table 1 lists these fungi, and as is shown, the $R$. arrhizus NRRL 2582 and R. oryzae ATCC 20344 gave the highest volumetric productivity, product titer, and product yield values (Gangl et al. 1990; Cao et al. 1996).

Despite the fact that the aforementioned experimental studies involve fungi, the use of bacteria has been considered as well. Donnelly et al. (2001) have suggested using a Lactobacillus host strain that lacks the malolactate enzyme, fumarase, and fumarate dehydrogenase. Introducing the maeA gene for the malic enzyme from Escherichia coli would result in a pathway from pyruvate to malate and hence in a malic acid-producing mutant. Additional genetic engineering would result in fumaric acid production.

Genetic modification of microorganisms has hardly been explored for fumaric acid production but offers a potentially useful approach solution for improving yields and rates in fermentation.

Table 1 Literature data on fumaric acid production by different Rhizopus genera

\begin{tabular}{|c|c|c|c|c|c|c|c|c|}
\hline Strain & Fermenter & Substrate & $\begin{array}{l}\text { Product Titer } \\
\left(\mathrm{g} \mathrm{l}^{-1}\right)\end{array}$ & $\begin{array}{l}\text { Yield } \\
\left(\mathrm{g} \mathrm{g}^{-1}\right)\end{array}$ & $\begin{array}{l}\text { Vol. Prod. } \\
\left(\mathrm{g} \mathrm{l}^{-1} \mathrm{~h}^{-1}\right)\end{array}$ & $\begin{array}{l}\text { Time } \\
\text { (h) }\end{array}$ & $\begin{array}{l}\text { Final } \\
\mathrm{pH}\end{array}$ & Reference \\
\hline \multirow[t]{2}{*}{ R. nigricans 45} & Shake flask & Glucose & 14.7 & 0.50 & - & 168 & 6.5 & Foster \& Waksman 1938 \\
\hline & Shake flask & Glucose & 20.0 & 0.66 & 0.25 & 80 & 6.5 & Romano et al. 1967 \\
\hline \multirow{3}{*}{ R. arrhizus NRRL 2582} & Stirred tank & Glucose & 90.0 & 0.70 & 1.22 & 72 & 6.0 & Rhodes et al. 1962 \\
\hline & Stirred tank & Glucose & 107.0 & 0.82 & 2.00 & 53 & 6.0 & $\mathrm{Ng}$ et al. 1986 \\
\hline & Stirred tank & Glucose & 73.0 & 0.72 & 0.50 & 147 & 5.5 & Gangl et al. 1990 \\
\hline \multirow[t]{3}{*}{ R. arrhizus NRRL 1526} & Shake flask & Glucose & 97.7 & 0.81 & 1.02 & 96 & 6.0 & Kenealy et al. 1986 \\
\hline & Fluidized bed & Molasses & 17.5 & 0.36 & 0.36 & 48 & 6.0 & Petruccioli et al. 1996 \\
\hline & Stirred tank & Glucose & 38.0 & 0.33 & 0.46 & 82 & 5.5 & Riscaldati et al. 2000 \\
\hline \multirow[t]{6}{*}{ R. oryzae ATCC 20344} & $\mathrm{RBC}^{\mathrm{a}}$ plus Adsorption & Glucose & 92.0 & 0.85 & 4.25 & 24 & 4.5 & Cao et al. 1996 \\
\hline & Stirred tank & Glucose & 65.0 & 0.65 & 0.90 & 72 & 5.0 & Cao et al. 1996 \\
\hline & $\mathrm{RBC}^{\mathrm{a}}$ & Glucose & 75.5 & 0.75 & 3.78 & 24 & 5.0 & Cao et al. 1997 \\
\hline & 10-1 air lift & Glucose & 37.8 & 0.75 & 0.81 & 46 & 5.0 & Du et al. 1997 \\
\hline & Stirred tank & Glucose & 35.8 & 0.60 & 0.90 & 40 & 5.5 & Zhou 1999 \\
\hline & Bubble column & Glucose & 37.2 & 0.53 & 1.03 & 36 & 5.0 & Zhou et al. 2002 \\
\hline R. formosa MUCL 28422 & Stirred tank & Cassava bagasse & 21.3 & - & - & - & 6.5 & Carta et al. 1999 \\
\hline
\end{tabular}

${ }^{\text {a }}$ Rotatory biofilm contactor 
Metabolic pathways to fumaric acid

Fumaric acid is primarily an intermediate of the citrate cycle, but is also involved in other metabolic pathways. In 1939, it was suggested that fumarate biosynthesis involved a C-2 plus C-2 condensation in Rhizopus species (Foster et al. 1949). The reactions in this pathway seemed to be similar to those of the glyoxylate bypass (Foster et al. 1949). Years after, the glyoxylate bypass mechanism was ruled out because the theoretical molar yield for this pathway of $100 \%$ was not in agreement with the experimental yield of 140\% (Rhodes et al. 1959; Romano et al. 1967). However, the main evidence for rejecting the glyoxylate bypass mechanism is that the key enzyme of the glyoxylate pathway, isocitrate-glyoxylate lyase, was repressed when high glucose concentrations were present like in the experiments used for fumaric acid production (Romano et al. 1967).

It was discovered that a $\mathrm{C}_{3}$ plus $\mathrm{C}_{1}$ mechanism involving $\mathrm{CO}_{2}$ fixation catalyzed by pyruvate carboxylase under aerobic conditions explained the high molar yields in fumarate production (Overman and Romano 1969). This $\mathrm{CO}_{2}$ fixation leads to oxaloacetic acid formation (Osmani and Scrutton 1985), so that $\mathrm{C}_{4}$ citrate cycle intermediates can be withdrawn for biosynthesis during the growth phase under aerobic conditions. When nitrogen becomes limiting and the growth phase stops, the metabolism of glucose and $\mathrm{CO}_{2}$ fixation could continue and lead to an accumulation of $\mathrm{C}_{4}$ acids (Romano et al. 1967). The maximal theoretical yield in a nongrowth situation is $2 \mathrm{~mol}$ of fumaric acid per mole of glucose consumed, upon fixation of $2 \mathrm{~mol}$ of $\mathrm{CO}_{2}$ via reductive pyruvate carboxylation. However, if the reductive pyruvate carboxylation would be the sole pathway, no ATP would be produced for maintenance or transport purposes. Therefore, the citrate cycle is also active during fumaric acid production (Rhodes et al. 1959; Kenealy et al. 1986).

The $\mathrm{CO}_{2}$ carboxylation enzyme, pyruvate carboxylase, is known to be localized exclusively in the cytosol, together with NAD-malate dehydrogenase and fumarase (that are present in the cytosol and in the mitochondria), leading to fumaric acid synthesis in this cell compartment (Osmani and Scrutton 1985). Studies performed by Peleg et al. (1989) indicated higher activities of these enzymes (especially the cytosolic isoenzymes) during fumaric acid production. Kenealy et al. (1986) used mitochondrial inhibitors to investigate their role in fumarate accumulation and found no direct involvement of such inhibitors of the citrate cycle in fumarate production. However, carbonlabeling studies have demonstrated the simultaneous utilization of both the citrate cycle and the reductive pyruvate carboxylation pathways under aerobic conditions (Fig. 3). Besides the localization of fumarase isoenzymes, it was

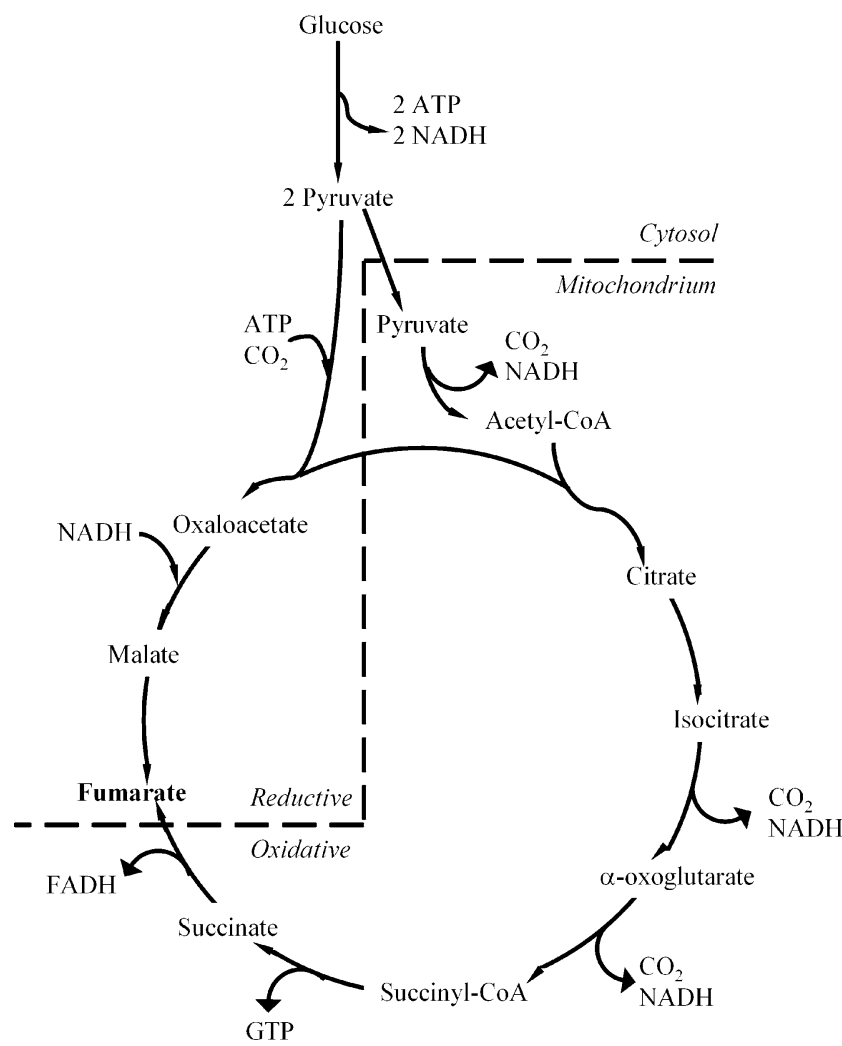

Fig. 3 Citrate cycle pathway and reductive carboxylation pathway leading to fumaric acid accumulation (adapted from Kenealy et al. 1986). The ratio between the two pathways is not $1: 1$ as suggested by this figure

also found that addition of cycloheximide virtually eliminated the cytosolic isoenzyme and therefore caused a large decrease in the amount of fumaric acid produced by $R$. oryzae (Peleg et al. 1989).

The carboxylation of pyruvate has been studied in more detail for the analogous microbial succinate production, but the understanding of the different metabolic fluxes involved is still incomplete (McKinlay et al. 2007).

High-producing fumaric acid strains of Rhizopus not only produce fumaric acid but also other carboxylic acids like malic, lactic, acetic, succinic, and citric in smaller amounts than fumaric acid production (Rhodes et al. 1959; Carta et al. 1999). Sometimes, ethanol is also produced, like in the case of the high-producing strain $R$. oryzae ATCC 20344 (Cao et al. 1996). However, it was found that ethanol production can be reduced by a sufficient supply of oxygen to the culture (Cao et al. 1996).

Fumaric acid transport across the cell membrane

The transport mechanism of fumaric acid in fungi has not been studied yet. However, transport of L-malic acid and other dicarboxylic acids, including fumaric acid, has been studied in yeasts like Schizosaccharomyces pombe, Candida utilis, Candida sphaerica, and Hansenula anomala 
(Corte-Real et al. 1989; Corte-Real and Leao 1990; Saayman et al. 2000). These microorganisms may be comparable to fumaric-producing fungi. These studies showed that the initial uptake of malic acid was accompanied by disappearance of extracellular protons suggesting that the anionic form of the acid was transported by an accumulative dicarboxylate proton symporter. As fumaric acid seems to be a competitive inhibitor of L-malic acid uptake, it was suggested that fumaric acid uses the same import system.

On the other hand, these studies showed that undissociated dicarboxylic acid entered the cells slowly by simple diffusion. In addition, it was revealed that the rate of diffusion of the undissociated acid across the plasma membrane is subjected to opposite $\mathrm{pH}$ influences: an increase due to the relative increase of undissociated acid with decreasing $\mathrm{pH}$ and a decrease due to a decrease of the permeability of the cell membrane for the undissociated acid at decreasing $\mathrm{pH}$ (Corte-Real and Leao 1990). Increasing the number or activity of the dicarboxylic acid transporters could lower the intracellular fumarate concentration and could therefore have a positive effect on the production yield (van Maris et al. 2004).

\section{Alternative fermentation feedstocks}

Glucose has not been the only carbon source used for fumaric acid-producing strains. The use of xylose with immobilized $R$. arrhizus was studied, but the highest obtained volumetric productivity was only $0.087 \mathrm{~g} \mathrm{l}^{-1} \mathrm{~h}^{-1}$ (Kautola and Linko 1989). Also, sucrose has been considered as a raw material in fumaric acid-production processes (Kautola and Linko 1989; Zhang et al. 2007), but sucrose has the disadvantage of being poorly metabolized by $R$. oryzae compared to glucose (Bulut et al. 2004).

Starch-containing materials were also screened as feedstock for the fumaric acid production. Potato flour was used as feedstock for $R$. arrhizus, and although fumaric acid was the main metabolic product, a volumetric productivity of only $0.35 \mathrm{~g} \mathrm{l}^{-1} \mathrm{~h}^{-1}$ was achieved (Moresi et al. 1991). On the other hand, it was found that the highest yields of fumaric acid were obtained from acid hydrolysates of starch-based materials (Moresi et al. 2002). The same feedstock was used by Federici et al. (1993) in studies on the effect of agitation speed and applied neutralizing agent. The tested neutralizing agent was a combination of $\mathrm{CaCO}_{3}$ and $\mathrm{KOH} / \mathrm{KCO}_{3}$, and it was concluded that comparable fumaric acid yields were obtained using these neutralizing agents and starch-based materials (Federici et al. 1993). Carta et al. (1999) optimized the fumaric acid production by $R$. formosa MUCL 28422 by using enzymatic hydrolysates of cassava bagasse, a high-starch-containing waste product. The productivity was not improved with respect to a fermentation where glucose was used as a feedstock, but the fact that these feedstocks are cheap and abundant makes these optimized fermentations economically attractive.

\section{Nutrient requirements}

Physical and nutritional requirements for fumaric acid fermentation have been studied in Rhizopus arrhizus (Rhodes et al. 1959; Rhodes et al. 1962). As Rhizopus species should enter a phase of limited growth during the fermentation, which can be achieved by nitrogen limitation, these studies showed that to achieve high yields during fumaric acid fermentation, the most critical parameter is the ratio of glucose to nitrogen. For example, a yield of fumaric acid on glucose of $85 \%(w / w)$ was obtained using an initial C:N molar ratio of 200:1 for $R$. arrhizus 2582. When nitrogen limitation is not desired, phosphorus limitation can be used instead (Riscaldati et al. 2000). Trace metal concentrations of $500 \mathrm{ppm}, 4 \mathrm{ppm}$, and $100 \mathrm{ppb}$ for $\mathrm{Mg}^{++}$, $\mathrm{Zn}^{++}$, and $\mathrm{Fe}^{++}$, respectively, were found optimal for the formation of small $(1 \mathrm{~mm})$ spherical pellets that produced high concentrations of fumaric acid (36 $\mathrm{g} \mathrm{L}^{-1}$; Zhou 1999).

Because $\mathrm{CO}_{2}$ is needed for the oxaloacetate formation from pyruvate by pyruvate carboxylase, the addition of calcium carbonate $\left(\mathrm{CaCO}_{3}\right)$, which is used in many cases as a neutralizing agent, seems also important as a $\mathrm{CO}_{2}$ source during the production phase of the fermentation. However, in case that no $\mathrm{CO}_{2}$ or carbonate is added, the complete catabolism of a mole of glucose via the citrate cycle provides $6 \mathrm{~mol}$ of $\mathrm{CO}_{2}$ that may be used for pyruvate carboxylation (see Fig. 3). In this case, the maximum theoretical yield would be $1.5 \mathrm{~mol}$ of fumaric acid per mole of glucose. This theoretical value is close to the value of $1.32 \mathrm{~mol}$ of fumaric acid per mole of glucose reported by Cao et al. (1996), who optimized a fermentation process without $\mathrm{CO}_{2}$ or carbonate feeding.

\section{Neutralizing agents}

Continuous neutralization of the $\mathrm{pH}$ has been necessary to obtain optimal yields in fumaric acid production by fermentation. Preferably, $\mathrm{CaCO}_{3}$ has been used as a neutralizing agent, but at the same time, this compound is causing viscosity problems due to the low aqueous solubility of calcium fumarate $\left[21 \mathrm{~g} / 1\right.$ at $30^{\circ} \mathrm{C}$ (Gangl et al. 1990)] that precipitates as a fermentation product. Furthermore, the cells can interact with the precipitated product, as has been found for $R$. oryzae, resulting in a highly viscous suspension. This has a detrimental effect on the rate of oxygen transfer which can be achieved, and hence, the fermentation might fail due to oxygen-limitation problems. Therefore, replacement of $\mathrm{CaCO}_{3}$ by other neutralizing agents like $\mathrm{Na}_{2} \mathrm{CO}_{3}, \mathrm{NaHCO}_{3}, \mathrm{Ca}(\mathrm{OH})_{2}$, and $\left(\mathrm{NH}_{4}\right)_{2} \mathrm{CO}_{3}$ has been studied by different authors (Gangl et 
al. 1990; Riscaldati et al. 2000; Zhou et al. 2002). However, these studies showed that the fumarate production rates are the highest when $\mathrm{CaCO}_{3}$ is used as a neutralizing agent.

Because of the high solubility of sodium fumarate, fermentative production of fumarate using $\mathrm{Na}_{2} \mathrm{CO}_{3}$ as neutralizing agent leads to cheaper downstream processing than when $\mathrm{CaCO}_{3}$ is used. This is due to the fact that the fermentation product, sodium fumarate, has a higher solubility than $\mathrm{CaCO}_{3}$, and hence, there is no need of heating to recover the fermentation product (see Fig. 4). In addition, cells can be reused (Gangl et al. 1990; Zhou et al. 2002). A similar situation was obtained when Rhizopus growth was limited by phosphorus so that $\left(\mathrm{NH}_{4}\right)_{2} \mathrm{CO}_{3}$ could be used as neutralizing agent (Riscaldati et al. 2000). Nevertheless, it has been argued that a fermentation process without the use of neutralizing agents, and at the same time preventing product inhibition, will improve the economics of the general process (Gangl et al. 1990). However, when a high-yield process is developed without a carbonate as neutralizing agent, the required $\mathrm{CO}_{2}$ must be supplied by other sources. Fumaric acid fermentation systems without the use of neutralizing agents have been studied in the past and will be discussed in the following sections.

With respect to fumarate salts inhibition, Rhodes et al. (1962) reported that production of soluble sodium or potassium fumarates was inhibited when the concentration of fumarate reached values of $34-40 \mathrm{~g} \mathrm{~L}^{-1}$ using $R$. arrhizus as a producer strain. Nonetheless, Gangl et al. (1990) found that addition of sodium fumarate $\left(71.3 \mathrm{~g} \mathrm{~L}^{-1}\right)$ was not inhibiting the same strain, although the cells needed $35 \mathrm{~h}$ to adapt to the high sodium fumarate concentrations. On the other hand, the free fumaric acid does inhibit its own production because the accumulated protons in the production medium decrease the $\mathrm{pH}$, thus exerting a progressive inhibitory effect on fumaric acid production (Riscaldati et al. 2000). At low $\mathrm{pH}$, excreted fumaric acid will passively diffuse back through the plasma membrane of the fungus decreasing its intracellular $\mathrm{pH}$, and due to this phenomenon, the fermentation fails. Proposed methods to enable carboxylic acid fermentation at low $\mathrm{pH}$ are: genetic engineering of acid tolerant organisms such as yeasts and in situ product removal techniques (Cao et al. 1996; Schügerl 2000; van Maris et al. 2004).

\section{Morphology and oxygen-transfer problems}

One of the difficulties of fermenting Rhizopus species is the morphology of these fungi. Rhizopus species tend to grow on the walls and on the stirrer of the reactor, and sometimes, clumps are formed. Therefore, the fermentation can suffer from oxygen limitation in particular when calcium fumarate is present. One way to solve this problem is to control the growth of the fungi and their morphology.

A way to minimize oxygen mass transfer limitation to the cells is to stimulate formation of small spherical cell pellets (Zhou 1999). Small pellets can reduce clump formation during fermentation, and even if $\mathrm{CaCO}_{3}$ is present, the viscosity of the broth can be reduced. Moreover, pellets can facilitate the performance of a biomass retention system. For $R$. oryzae, low initial $\mathrm{pH}$ values for the cultivation media favored pellet formation, and good fumaric acid yields have been reached (Zhou et al. 2000).

In another morphology improvement study, Cao et al. (1997) used a rotary biofilm contactor (RBC) as fermentor with immobilized $R$. oryzae to produce fumaric acid. $\mathrm{CaCO}_{3}$ was used as neutralizing agent during this experiment. During the fermentation, the discs with immobilized cells were rotating, moving the cells from the gas phase of the fermentor to the liquid phase and back again (Cao et al. 1997). When the cells are exposed to the air, high oxygen transfer rates can be reached, while the cells can take up substrate and excrete the produced fumaric acid when they are submerged. In this system, additional agitation was not needed. The volumetric productivity was very high, compared to the volumetric productivity of an equivalent stirred vessel fermentor setup (see Table 1). A disadvantage of this system could be the scalability potential of the RBC fermentor.

Fig. 4 Flow-sheet for fumaric acid production via fermentation. $a$ Formulation tanks containing glucose and nutrients; $b$ Seed fermentor; $c$ Production fermentor; $d$ Filter; $e$ Acidification tank; $f$ Filter; $g$ Rotary dryer (adapted from Gangl et al. 1990)

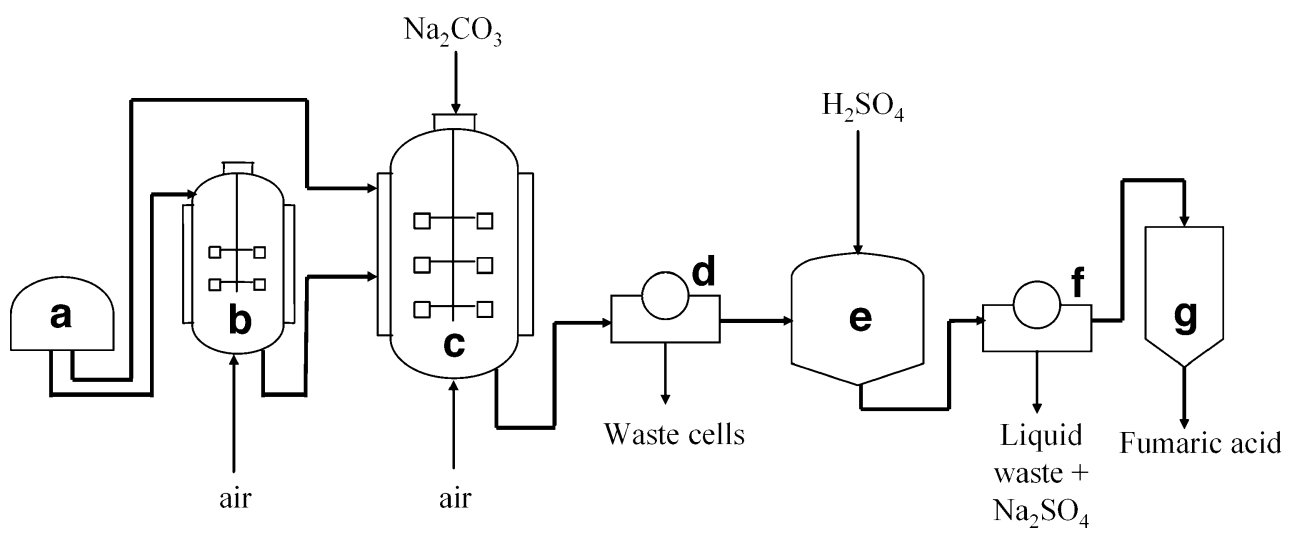


Immobilization techniques for Rhizopus species have been investigated to open the possibility of a continuous operation mode for fumaric acid production and to reduce oxygen transfer problems as well. Buzzini et al. (1995) searched for the most suitable support for cell immobilization in fluidized-bed reactors during fumaric acid fermentation. Cork, expanded polystyrene, expanded clay, and wood shavings were investigated. With $6 \mathrm{~mm}$ pieces of cork, the highest titer, $24.1 \mathrm{~g}$ fumaric acid $\mathrm{l}^{-1}$ in $144 \mathrm{~h}$, was achieved, which is comparable to the titer of $37.7 \mathrm{~g}^{-1}$ after $166 \mathrm{~h}$ under conventional submerged conditions (Buzzini et al. 1995). The performance of a semi-continuous process was investigated with $R$. arrhizus immobilized on $5 \mathrm{~mm}$ cubic particles made of polyurethane sponge (Petruccioli et al. 1996). These particles were used in repeated batch fermentations in a fluidized-bed reactor ( $48 \mathrm{~h}$, eight times). In the optimized process, the fumaric acid titer was $12.3 \mathrm{~g} \mathrm{l}^{-1}$, and the volumetric productivity was $0.256 \mathrm{~g} \mathrm{l}^{-1} \mathrm{~h}^{-1}$.

Furthermore, as the oxygen mass transfer resistance through the boundary layer on the liquid side of the gas-liquid interface can affect the interfacial oxygen transfer from the gas phase to the liquid phase, pressure pulsation was applied in a stirred tank fermentor using R. oryzae (Zhou 1999) to reduce this resistance. Mass yield and volumetric productivity of fumarate were $70.1 \%$ and $0.99 \mathrm{~g} \mathrm{~L}^{-1} \mathrm{~h}^{-1}$, respectively, which were higher than for traditional stirred tank fermentations. The same organism was studied in an airlift loop reactor as a fermentation system for fumaric acid production (Du et al. 1997). Here, the airlift loop reactor with porous sparger produced favorable conditions for mass transfer, and also, higher yields and productivities were reached than in stirred tank fermentations.

Integrated fermentation and recovery of fumaric acid

Figure 4 presents a flow scheme proposed for fumaric acid production by batch fermentation (Gangl et al. 1990). Glucose and mineral salts are fed to the fermentor. The nitrogen source solution, $\left(\mathrm{NH}_{4}\right)_{2} \mathrm{SO}_{4}$, is sterilized separately and fed to the seed fermentor. The harvested broth containing sodium fumarate (cells and trace amounts of $\mathrm{Na}_{2} \mathrm{CO}_{3}$ ) is filtered to remove the cells and then acidified by $\mathrm{H}_{2} \mathrm{SO}_{4}$ to $\mathrm{pH} 1$. After acidification, fumaric acid precipitates out of the solution and is sent to a rotary dryer to be completely recovered (Gangl et al. 1990). When $\mathrm{CaCO}_{3}$ is used as a neutralizing agent instead of $\mathrm{Na}_{2} \mathrm{CO}_{3}$, additional heating after the fermentation was supposed to be required to dissolve calcium fumarate and the excess of $\mathrm{CaCO}_{3}$ that usually stick to the cells. This problem leads to a tedious and expensive downstream processing.

In the downstream processing field, recovery techniques have not so much been studied for fumaric acid producers in submerged cultivations as it has been done for related fermentation products like succinic acid (Zeikus et al. 1999), citric acid (Heinzle et al. 2006), and lactic acid (Joglekar et al. 2006). Recovery systems like reactive extraction and membrane electrodialysis have not been studied yet. However, simultaneous fermentation and adsorption have been studied to remove fumaric acid during its formation to control fermentation $\mathrm{pH}$ at desired values and avoid product inhibition (Cao et al. 1996; Zhou 1999).

Cao et al. (1996) used a rotary biofilm contactor (RBC) setup as fermentor for $R$. oryzae, in combination with an adsorption column. The produced fumaric acid was removed from the broth by the adsorption column in a recycle loop, reducing product inhibition and thus increasing the production rate and sustaining cell viability. Polyvinyl pyridine (PVP) anion exchange resin in the hydroxide form was selected as adsorbent because it yielded the highest loading capacity for fumaric acid $\left(0.31 \mathrm{~g} \mathrm{~g}^{-1}\right.$ dry wt). The RBC, coupled with the adsorption column, increased the fumaric acid productivity significantly to $4.25 \mathrm{~g} \mathrm{l}^{-1} \mathrm{~h}^{-1}$ because the total fermentation time was much less than in traditional stirred tank fermentations (see Table 1). This volumetric productivity and the yield are the highest reported in literature. In this integrated system, the constant removal of the fumarate produced and the liberation of $\mathrm{OH}^{-}$from the adsorption column kept the fermentation $\mathrm{pH}$ at 4.5 . The fumarate was desorbed from the adsorption resin by using $0.4 \mathrm{M} \mathrm{NaOH}$ so additional processing will be necessary to convert the sodium fumarate into neutral fumaric acid. Addition of extra $\mathrm{CO}_{2}$ was not necessary due to the fact that during the production stage, the biofilm was exposed to sterile air that was present in the headspace of the RBC enhancing the opportunity for $\mathrm{CO}_{2}$ fixation by the biofilm.

Table 2 Comparison between petrochemical and fermentation route for fumaric acid production

\begin{tabular}{lll}
\hline Parameter & Petrochemical route & Fermentation route \\
\hline Raw material & Maleic anhydride & Glucose \\
Reaction temperature $\left({ }^{\circ} \mathrm{C}\right)$ & $90-100$ & 35 \\
Raw material price $(\$ / \mathrm{kg})$ & $1.46-1.63$ (Anonymous 2007) & $0.46^{\mathrm{a}}$ \\
Product yield $(\% w / w)$ & 112 (Lohbeck et al. 1990) & $85($ Cao et al. 1996)
\end{tabular}

${ }^{\mathrm{a}}$ http://www.ers.usda.gov/briefing/sugar/data.htm; for 4th quarter of 2006 
A novel product recovery process by an ion exchanger resin was developed by Zhou (1999). Fumarate was recovered from the fermentation broth without the use of neutralizing agents, while keeping the $\mathrm{pH}$ at 5 , by cycling the broth over a column of a resin (Amberlite IRA-900 with $\mathrm{OH}^{-}$as counterion). After eluting the loaded column with ammonium hydroxide, ammonium fumarate solution was obtained. This was passed through a Y-zeolite column that retained the ammonium and liberated the fumaric acid. The ammonium hydroxide solution can be recovered and recycled by thermal regeneration of the zeolite (Zhou 1999). However, this integrated process did not surpass yield values obtained in a stirred tank fermentor when fumaric acid fermentation was controlled by $\mathrm{CaCO}_{3}$ under pressure pulsation (see previous section), but a higher productivity value of $1.09 \mathrm{~g} \mathrm{~L}^{-1} \mathrm{~h}^{-1}$ was reached (Zhou et al. 2000).

\section{Economics of fumaric acid production}

In a theoretical study, Gangl et al. (1990) compared a fermentation and a benzene-based petrochemical process with respect to economy. The fermentation process taken for this has been described in the beginning of the previous section. Although $\mathrm{Na}_{2} \mathrm{CO}_{3}$ was assumed as a neutralizing agent in this study, the productivity $\left(2 \mathrm{~g} \mathrm{l}^{-1} \mathrm{~h}^{-1}\right)$ and yield $\left(0.82 \mathrm{~g} \mathrm{~g}^{-1}\right)$ of the fumaric acid fermentation with $\mathrm{CaCO}_{3}$ obtained in a previous study were used ( $\mathrm{Ng}$ et al. 1986).

This economic evaluation showed that the fermentation route was less favorable than the petrochemical route (economic evaluation included upstream and downstream sections). In particular, the raw material costs were higher for the fermentation process than for the petrochemical route. It was concluded that the fermentation route could become competitive with the petrochemical route if oil prices were around $61 \$ /$ barrel. The latter price has been reached in the recent years (http://tonto.eia.doe.gov/dnav/ pet/xls/PET_PRI_WCO_K_W.xls), while the productivity of the fermentation process has been improved significantly as is shown in Table 1. Besides, one can roughly calculate from Gangl's study that the assumed sugar price was around $0.6 \$ / \mathrm{kg}$ of glucose, which is high compared to the current price (see Table 2). Therefore, if the current glucose price is assumed in the calculations of Gangl's study, one can expect lower raw material costs for the fermentation route. On the other hand, the petrochemical route has also been improved significantly, now using butane instead of benzene. This will be reflected in the current maleic anhydride price, which is shown in Table 2.

The simple comparison of petrochemical and fermentation routes for fumaric acid production given in Table 2 suggests that the lower raw material price of the fermentative production might compensate the higher yields of the petrochemical production from maleic anhydride, and fermentation may become an economically viable alternative.

\section{Conclusions and future prospects}

Due to increasing prices of fossil feedstock, fermentatively produced fumaric acid could become a cheaper alternative to the petrochemically based maleic acid as unsaturated dibasic acid in polyester resins in the nearby future. Based on the available literature, the microorganism with the highest productivity and yield of fumaric acid appears to be $R$. oryzae. This organism produces fumaric acid via a combination of the citrate cycle and reductive pyruvate carboxylation. In addition, the fumaric acid production by fermentation can be improved if the use of neutralizing agents is reduced or avoided and the morphology of the fungi is optimized. However, avoiding the use of a neutralizing agent will lead to product inhibition; therefore, it would be useful if metabolic engineering is applied to achieve fumaric acid production in suspended, acid-resistant microorganisms such as yeast. Another way to solve product inhibition problems is applying in situ removal of fumaric acid during the fermentation.

Acknowledgements This project is financially supported by the Netherlands Ministry of Economic Affairs and the B-Basic partner organizations (www.b-basic.nl) through B-Basic, a public private NWO-ACTS programme (ACTS: Advanced Chemical Technologies for Sustainability).

Open Access This article is distributed under the terms of the Creative Commons Attribution Noncommercial License which permits any noncommercial use, distribution, and reproduction in any medium, provided the original author(s) and source are credited.

\section{References}

Altmeyer PJ, Matthes U, Pawlak F, Hoffmann K, Frosch PJ, Ruppert P, Wassilew SW, Horn T, Kreysel HW, Matthes U, Pawlak F, Rietzschel I, Joshi RK (1994) Antipsoriatic effect of fumaric acid derivatives - results of multicenter double blind study in 100 patients. J Am Acad Dermatol 30:977-981

Anonymous (2007) Product focus: Maleic anhydride. Chem Week 39

Bulut S, Elibol M, Ozer D (2004) Effect of different carbon sources of $\mathrm{L}(+)$-lactic acid production by Rhizopus oryzae. Biochem Eng J 21:33-37

Buzzini P, Gobbetti M, Rossi J, Ribaldi M (1995) Comparison in different unconventional supports for the immobilization of Rhizopus arrhizus cells to produce fumaric acid on grape must. Ann Microbiol Enzymol 43:53-60

Cao NJ, Du JX, Gong CS, Tsao GT (1996) Simultaneous production and recovery of fumaric acid from immobilized Rhizopus oryzae with a rotary biofilm contactor and an adsorption column. Appl Environ Microbiol 62:2926-2931

Cao NJ, Du JX, Chen CS, Gong CS, Tsao GT (1997) Production of fumaric acid by immobilized Rhizopus using rotary biofilm contactor. Appl Biochem Biotechnol 63-5:387-394 
Carta FS, Soccol CR, Ramos LP, Fontana JD (1999) Production of fumaric acid by fermentation of enzymatic hydrolysates derived from cassava bagasse. Bioresource Technol 68:23-28

Corte-Real M, Leao C (1990) Transport of malic acid and other carboxylic acids in the yeast Hansenula anomala. Appl Environ Microbiol 56:1109-1113

Corte-Real M, Leao C, van Uden N (1989) Transport of L-malic acid and other dicarboxylic acids in the yeast Candida sphaerica. Appl Microbiol Biotechnol 31:551-555

Donnelly M, Millard CS, Stols L (2001) Mutant E. Coli strain with increased succinic acid production. USRE37393

Du JX, Cao NJ, Gong CS, Tsao GT, Yuan NJ (1997) Fumaric acid production in airlift loop reactor with porous sparger. Appl Biochem Biotech 63-65:541-556

Federici F, Moresi M, Parente E, Petruccioli M, Piccioni P (1993) Effect of stirring rate and neutralising agent on fumaric acid production by Rhizopus arrhizus. Ital J Food Sci 4:387-396

Felthouse TR, Burnett JC, Horrell B, Mummey MJ and Kuo YJ (2001) Maleic anhydride, maleic acid, and fumaric acid. Kirk-Othmer encyclopedia of chemical technology, 4th edn., Vol 15, 1-58

Foster JW, Waksman SA (1938) The production of fumaric acid by molds belonging to the genus Rhizopus. J Am Chem Soc 61:127-1

Foster JW, Carson SF, Anthony DS, Davis JB, Jefferson WE, Long MV (1949) Aerobic formation of fumaric in the mold Rhizopus nigricans - synthesis by direct C-2 condensation. Proc Natl Acad Sci USA 35:663-672

Gangl IC, Weigand WA, Keller FA (1990) Economic comparison of calcium fumarate and sodium fumarate production by Rhizopus arrhizus. Appl Biochem Biotechnol 24-25:663-677

Goldberg I, Stieglitz B (1986) Fermentation process for production of carboxylic acids. US4564594

Goldberg I, Rokem JS, Pines O (2006) Organic acids: old metabolites, new themes. J Chem Tech Biotechnol 81:1601-1611

Goto M, Nara T, Tokumaru I, Fugono N, Uchida Y, Terasawa M, Yukawa H (1998) Method of producing fumaric acid. US5783428

Heinzle E, Biwer AP, Cooney CL (2006) Development of sustainable bioprocess - modelling and assessment. Wiley, Chichester

Ichikawa S, Iino T, Sato S, Nakahara T, Mukataka S (2003) Improvement of production rate and yield of fumaric acid from maleic acid by heat treatment of Pseudomonas alcaligenes strain XD-1. Biochem Eng J 13:7-13

Joglekar HG, Rahman I, Babu S, Kulkarni BD, Joshi A (2006) Comparative assessment of downstream processing options for lactic acid. Sep Purif Technol 52:1-17

Kane JH (1943) Production of fumaric acid. US2327191

Kautola H, Linko YY (1989) Fumaric acid production from xylose by immobilized Rhizopus arrhizus cells. Appl Microbiol Biotechnol $31: 448-452$

Kenealy W, Zaady E, Dupreez JC, Stieglitz B, Goldberg I (1986) Biochemical aspects of fumaric acid accumulation by Rhizopus arrhizus. Appl Environ Microbiol 52:128-133

La Roe EG (1959) Fumaric acid fermentation process. US2912363

Ling LB, Ng TK (1989) Fermentation process for carboxylic acids. US4877731

Lubowitz HR, La Roe EG (1958) Fumaric acid fermentation process. US2861922

Lohbeck K, Haferkorn H, Fuhrmann W, Fedtke N (1990) Maleic and fumaric Acids. Ullmann's Encyclopedia of Industrial Chemistry, vol. A16. VCH, Weinheim, Germany, pp 53-62

Magnuson JK, Lasure LL (2004) Organic acid production by filamentous fungi. In: Tracz JS, Lange L (eds) Advances in fungal biotechnology for industry, agriculture and medicine. Kluwer/Plenum, New York, USA, pp 307-340

Mcginn SM, Beauchemin KA, Coates T, Colombatto D (2004) Methane emissions from beef cattle: Effects of monensin, sunflower oil, enzymes, yeast and fumaric acid. J Anim Sci 82:3346-3356

McKinlay JB, Vieille C, Zeikus JG (2007) Prospects for a bio-based succinate industry. Appl Microbiol Biotechnol 76:727-740

Moresi M, Parente E, Petruccioli M, Federici F (1991) Optimization of fumaric acid production from potato flour by Rhizopus arrhizus. Appl Microbiol Biotechnol 36:35-39

Moresi M, Ceccantoni B, Lo Presti S (2002) Modelling of ammonium fumarate recovery from model solutions by nanofiltration and reverse osmosis. J Membrane Sci 209:405-420

Mrowietz U, Christophers E, Altmeyer P (1998) Treatment of psoriasis with fumaric acid esters: results of a prospective multicentre study. Brit J Dermatol 138:456-460

NakajimaKambe T, Nozue T, Mukouyama M, Nakahara T (1997) Bioconversion of maleic acid to fumaric acid by Pseudomonas alcaligenes strain XD-1. J Ferment Bioeng 84:165-168

Ng TK, Hesser RJ, Stieglitz B, Griffiths BS, Ling LB (1986) Production of tetrahydrofuram $/ 1,4$ butanediol by a combined biological and chemical process. Biotech Bioeng Symp 17:344-363

Osmani SA, Scrutton MC (1985) The sub-cellular localization and regulatory properties of pyruvate carboxylase from Rhizopus arrhizus. Eur J Biochem 147:119-128

Otsuka K (1961) Cis-trans isomerase-isomerisation from maleic acid to fumaric acid. Agric Biol Chem 25:726

Overman SA, Romano AH (1969) Pyruvate carboxylase of Rhizopus nigricans and its role in fumaric acid production. Biochem Biophys Res Commun 37:457-463

Peleg Y, Battat E, Scrutton MC, Goldberg I (1989) Isoenzyme pattern and subcellular localization of enzymes involved in fumaric acid accumulation by Rhizopus oryzae. Appl Microbiol Biotechnol 32:334-339

Petruccioli M, Angiani E, Federici F (1996) Semi continuous fumaric acid production by Rhizopus arrhizus immobilized in polyurethane sponge. Process Biochem 31:463-469

Rhodes RA, Moyer AJ, Smith ML, Kelley SE (1959) Production of fumaric acid by Rhizopus arrhizus. Appl Microbiol 7:74-80

Rhodes RA, Lagoda AA, Jackson RW, Misenhei TJ, Smith ML, Anderson RF (1962) Production of fumaric acid in 20 liter fermentors. Appl Microbiol 10:9-15

Riscaldati E, Moresi M, Federici F, Petruccioli M (2000) Direct ammonium fumarate production by Rhizopus arrhizus under phosphorous limitation. Biotechnol Lett 22:1043-1047

Romano AH, Bright MM, Scott WE (1967) Mechanism of fumaric acid accumulation in Rhizopus nigricans. J Biotechnol 93:600 604

Saayman M, van Vuuren HJJ, van Zyl WH, Viljoen-Bloom M (2000) Differential uptake of fumarate by Candida utilis and Schizosaccharomyces pombe. Appl Microbiol Biotechnol 54:792-798

Scher M, Lennarz WJ (1969) Maleate isomerase. J Biol Chem 244:1878-1872

Schügerl K (2000) Integrated processing of biotechnology products. Biotechnol Adv 18:581-599

Stephen WI (1965) Solubility and pH calculations. Anal Chim Acta 33:227

Takamura Y, Takamura T, Soejima M, Uemura T (1969) Studies on induced synthesis of maleate cis-trans isomerase by malonate. Purification and properties of maleate cis-trans isomerase induced by malonate. Agric Biol Chem 33:718

van Maris AJA, Konings WN, van Dijken JP, Pronk JT (2004) Microbial export of lactic and 3-hydroxypropanoic acid: implications for industrial fermentation processes. Metab Eng 6:245-255

Waksman SA (1943) Process for the production of fumaric acid. US2326986

Werpy T, Petersen G (2004) Top ten value added chemicals from biomass feedstocks. U.S. Department of Energy, USA 
Willke T, Vorlop K-D (2004) Industrial bioconversion of renewable resources as an alternative to conventional chemistry. Appl Microbiol Biotechnol 66:131-142

Zeikus JG, Jain MK, Elankovan P (1999) Biotechnology of succinic acid production and markets for derived industrial products. Appl Microbiol Biotechnol 51:545-552

Zhang ZY, Jin B, Kelly JM (2007) Production of lactic acid and byproducts from waste potato starch by Rhizopus arrhizus: role of nitrogen sources. World J Microbiol Biotechnol 23:229-236
Zhou Y (1999) Fumaric acid fermentation by Rhizopus oryzae in submerged systems. PhD thesis. Purdue University. West Lafayette, Indiana, USA

Zhou Y, Du JX, Tsao GT (2000) Mycelial pellet formation by Rhizopus oryzae ATCC 20344. Appl Biochem Biotechnol 84 86:779-789

Zhou Y, Du J, Tsao GT (2002) Comparison of fumaric acid production by Rhizopus oryzae using different neutralizing agents. Bioproc Biosyst Eng 25:179-181 